\title{
Evaluation of damage in front of starting notches induced by ultra-short pulsed laser ablation for the determination of fracture toughness in zirconia
}

\author{
Miquel Turon-Vinas ${ }^{\mathrm{a}, \mathrm{b}, *}$, José Morillas ${ }^{\mathrm{a}}$, Pablo Moreno ${ }^{\mathrm{c}}$, Marc Anglada ${ }^{\mathrm{a}, \mathrm{b}}$ \\ a CIEFMA, Department of Materials Science and Metallurgy, EEBE, Universitat Politècnica de Catalunya, C/d'Eduard Maristany, 10-14, 08930, Barcelona, \\ Spain \\ ${ }^{\mathrm{b}}$ Barcelona Research Center in Multiscale Science and Engineering, Universitat Politècnica de Catalunya, C/d'Eduard Maristany, 10-14, 08930, Barcelona, \\ Spain \\ c Grupo de Aplicaciones del Láser y Fotónica, ALF, Universidad de Salamanca, Pl. La Merced SN, E-37008 Salamanca, Spain
}

\section{A R T I C L E I N F O}

\section{Article history:}

Received 12 May 2017

Received in revised form 26 June 2017

Accepted 8 July 2017

Available online 15 July 2017

\section{Keywords:}

Ceramics

3Y-TZP

Fracture toughness

Laser damage

Notch

\begin{abstract}
A B S T R A C T
Machining a very sharp notch on the surface of ceramics for fracture toughness testing has been a critical issue during many years. In this work, we explore a novel method capable of inducing sharp features with negligible damage with laser pulsed ablation. We study the effect of different laser ablation parameters in the notch length and damage induced in $3 \mathrm{~mol} \%$ yttria doped zirconia. In front of the notch it is found a very narrow microcracked zone which spreads in the notch direction, whose length only depends on the laser pulse energy; meanwhile the length of the notch is proportional to the energy deposited during the process.
\end{abstract}

(c) 2017 Elsevier Ltd. All rights reserved.

\section{Introduction}

Fracture toughness of ceramics is usually determined by the single edge V-notch beam (SEVNB) method [1]. The notch is made with a saw cut and its tip is thinned by honing with a razor blade impregnated with a diamond slurry [2], [3]. By doing so, a relative sharp notch tip is finally achieved, and a number of microcracks, with a size typically 1-3 times the grain size, can be left in front of the notch tip by the machining process [4]. For the determination of $K_{I c}$ by this method, the stress intensity factor of this configuration of notch plus microcracks can be taken as that of a straight sharp crack as far as the length of the microcracked zone is longer than the notch tip radius [5]. This condition can be fulfilled in coarse grain size ceramics but it cannot be obeyed when the grain size is in the microscale or below, since then the radius of the notch tip should be smaller than is practically possible to achieve by honing.

\footnotetext{
* Corresponding author at. Department of Materials Science and Metallurgy, EEBE, Universitat Politècnica de Catalunya, C/d'Eduard Maristany, 10-14, 08930 Barcelona, Spain

E-mail address: miquel.turon@upc.edu (M. Turon-Vinas).
}

This makes machining sharp notches in sub-micrometer grain size ceramics for fracture toughness testing a critical issue.

One way of machining a very sharp notch on the surface of ceramics is ultrashort pulsed laser ablation (UPLA), which, in principle, is a technique capable of inducing very sharp features with negligible damage [6-8]. It is then an appealing technique for inducing a very sharp starting notch for measuring fracture toughness [9-12].

With UPLA the material is removed by direct vaporization and the heat affected zone is expected to be extremely small as compared to other techniques, provided the deposition of laser energy on the surface of the material occurs in a timescale which is much shorter than the typical time for energy transfer between electrons and lattice. Therefore, the material leaves the irradiated zone by either Coulomb or phase explosion mechanisms, depending on the density of energy of the laser on the surface [13], [14], and the rest of the material remains almost unaltered.

UPLA has been used for the production of high quality microstructures (grooves and pores) on the surface of cylindrical $3 \mathrm{~mol} \%$ yttria (3Y-TZP) dental implants [15]. In a previous work [9], [10] we have determined the fracture toughness of this material from surface sharp notches induced by UPLA. Here the attention is focused on studying the change in notch length and damage in 
a)

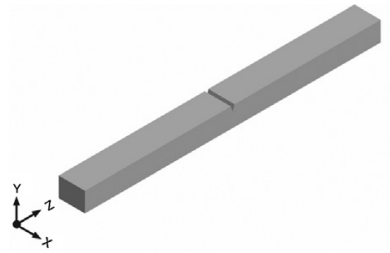

b)

$\stackrel{Y}{\longrightarrow} \mathrm{Z}$

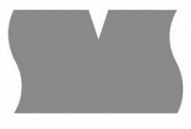

Fig. 1. Schematic view of the prismatic samples and the notch configuration: a) isometric view and b) lateral view focused on the notch.

front of notches machined under different laser ablation parameters. The change in the microstructure in front of the notch tip is here analysed by SEM-FIB showing that it consists mainly of a very narrow short microcracked band extended in the direction of the notch. The possible influence of this damage in the determination of fracture toughness is discussed.

\section{Experimental procedure}

Commercial powder 3Y-TZP (grade TZ-3YSB-E, Tosoh) was cold uniaxially pressed at $100 \mathrm{MPa}$ and sintered at $1450^{\circ} \mathrm{C}$ with heating and cooling rates of $3^{\circ} \mathrm{C} / \mathrm{min}$ and $1 \mathrm{~h}$ of maintenance, obtaining prismatic bars of $4 \mathrm{~mm} \times 3 \mathrm{~mm} \times 45 \mathrm{~mm}$ (directions $\mathrm{X}, \mathrm{Y}$ and $\mathrm{Z}$, respectively, see Fig. 1) with a density above $5.95 \mathrm{~g} / \mathrm{cm}^{3}$ as measured by the Archimedes method, and a grain size of about $330 \mathrm{~nm}$. All specimens were chamfered, and all surfaces were ground and polished following the standard methods up to $3 \mu \mathrm{m}$ finishing.

Small notches were laser machined on the XZ surface of the samples by UPLA, as pictured in Fig. 1. The ablation was carried out with infrared ultra-short laser pulses ( $120 \mathrm{fs}, 795 \mathrm{~nm}$ ) along the Ydirection (Fig. 1). The system used was a commercial Ti: Sapphire oscillator (Tsunami, Spectra Physics) and a regenerative amplifier system (Spitfire, Spectra Physics) based on chirped pulsed amplification. The pulses were linearly polarized and the repetition rate was $1 \mathrm{kHz}$. The focusing system used was an achromat doublet lens with $50 \mathrm{~mm}$ focal length. The samples were placed on a XYZ motorized stage and moved along the X-direction. The notches for the fracture toughness determination were produced using a pulse energy of $5 \mu \mathrm{J}$, scanning speed of $50 \mu \mathrm{m} / \mathrm{s}$ and four passes. In one of the samples, several notches were produced using different laser parameters in order to investigate the damage, as summarized in Table 1.

Two notches, 7 and 13 of Table 1, were selected for deeper observation, since they correspond to the lowest and highest total energies delivered for producing the notch. Field Emission Scanning Electron Microscopy (FESEM, JEOL) was used for a visual examination of the notches. First, a few tens of microns were removed from the YZ lateral surface by grinding and polishing to observe the damage in the interior of the sample and to avoid any edge effect on the notch fabrication and the consequent damage.

The tomography study of the microcracked area in front of the two notches was made using a dual beam Scanning Electron Microscope/Focused Ion Beam (FIB/SEM, Neon40, Zeiss), using a $\mathrm{Ga}^{+}$ion column. A platinum layer was deposited on the surface prior milling to reduce the curtain effect. Slices on the XZ plane with a thickness of $12 \mathrm{~nm}$ were milled using a current of $500 \mathrm{pA}$ in the $\mathrm{Y}$ direction (Fig. 1). The volumes involved in the study were $5.7 \times 9.3 \times 8.1 \mu \mathrm{m}^{3}$ for notch 7 and $5.7 \times 25.7 \times 8.1 \mu \mathrm{m}^{3}$ in the case of notch 13 .

FEI Avizo software was used to stack the slices and to create a segmented surface of the microcracks. Few prior gaussian and edge-preserving filters were required in order to improve image quality and erase artifacts.

\section{Results and discussion}

Fig. 2 shows a general view of the notches. In front of each one there is always a small microcracked band. It can be seen in Table 2 that the lengths of the notches are between $\sim 10 \mu \mathrm{m}$ and $29 \mu \mathrm{m}$ and that the microcracked bands are between $\sim 7.3$ and $24 \mu \mathrm{m}$ in the direction of the notch. There is also a correspondence between the laser energy deposited and the dimensions of the notches and microcracked bands so that the two notches produced with the lowest and highest laser pulse energies (number 7 and 13) are also the ones with shorter and longer total damage (notch + length of microcracked band).

Taking into account laser pulse energy, scanning speed, number of passes, pulse duration, and an estimated energy loss of $8 \%$ after the laser light passes through the focalization system (see Table 1), the total radiation energy per unit of length can be obtained and plotted as a function of notch depth (Fig. 3a). As expected, the notch depth increases with the radiation energy per unit of length.

However, the size of the damage in front of the notch does not depend on the total energy, since it does not change with the number of pulses per unit of length. It varies only with the energy of the pulse, as it can be observed in Fig. $3 \mathrm{~b}$ where the microcracked band length in front of the notch is plotted in terms of the number of pulses per unit length. Therefore, scanning speed and number of passes has no effect on the extent of damage observed. The average extension of the microcracked band length is plotted in Fig. $3 \mathrm{c}$ in terms of the pulse energy.

In Fig. 4a notches 7 and 13 with their microcracked bands are shown in more detail. The tomographic analysis was carried out in the slab indicated by the rectangle drawn in front of the notch with dimensions of $5.7 \mu \mathrm{m} \times 9.3 \mu \mathrm{m}$ in the YZ plane and with a depth along the X-direction of $\sim 8.1 \mu \mathrm{m}$ in the case of notch 7 . In the case of notch 13 (right) the same dimensions as for notch 7 with the exception of the length in the $Z$ direction was now $\sim 25.7 \mu \mathrm{m}$ since micro-cracking was detected up to $\sim 24 \mu \mathrm{m}$ from the notch root. Two videos on the 3D reconstruction of the microcracked zone are incorporated as supplementary material which gives light on the shape and interconnection of the cracks.

In order to compare both notches, a region of interest was defined as that which encloses all the cracked region in front of the notch. The beginning is arbitrarily defined as the location where the surfaces of the notch are opened by a gap of $2 \mu \mathrm{m}$, and it extends below the notch tip until no damage is detected. This was done to avoid some ambiguity in the detection of the true notch tip in some notches.

The slabs in front of the notch were sectioned along planes perpendicular to the notch (plane XZ, see Fig. 1) and the cracked area in each slice was measured. The fraction of cracked area detected

Table 1

Parameters used for the ablation of the notches (pulse duration $120 \mathrm{fs}$, wave length $795 \mathrm{~nm}$, repetition rate $1 \mathrm{KHz}$, spot radius $2.8 \mu \mathrm{m}$ ).

\begin{tabular}{|c|c|c|c|c|c|c|c|c|c|c|c|c|c|c|c|c|c|c|}
\hline Notch Number & 1 & 2 & 3 & 4 & 5 & 6 & 7 & 8 & 9 & 10 & 11 & 12 & 13 & 14 & 15 & 16 & 17 & 18 \\
\hline Pulse energy $(\mu \mathrm{J})$ & 5 & 5 & 5 & 5 & 5 & 5 & 3 & 3 & 3 & 3 & 3 & 3 & 8 & 8 & 8 & 8 & 8 & 8 \\
\hline Average power $(\mathrm{mW})$ & 5 & 5 & 5 & 5 & 5 & 5 & 3 & 3 & 3 & 3 & 3 & 3 & 8 & 8 & 8 & 8 & 8 & 8 \\
\hline Scanning speed $(\mu \mathrm{m} / \mathrm{s})$ & 50 & 50 & 100 & 100 & 150 & 150 & 150 & 150 & 100 & 100 & 50 & 50 & 50 & 50 & 100 & 100 & 150 & 150 \\
\hline Number of passes & 4 & 2 & 2 & 4 & 4 & 2 & 2 & 4 & 4 & 2 & 2 & 4 & 4 & 2 & 2 & 4 & 4 & 2 \\
\hline Pulses per linear micron & 80 & 40 & 20 & 40 & 27 & 13 & 13 & 27 & 40 & 20 & 40 & 80 & 80 & 40 & 20 & 40 & 27 & 13 \\
\hline Energy per linear micron (mW) & 400 & 200 & 100 & 200 & 133 & 67 & 40 & 80 & 120 & 60 & 120 & 240 & 640 & 320 & 160 & 320 & 213 & 107 \\
\hline
\end{tabular}




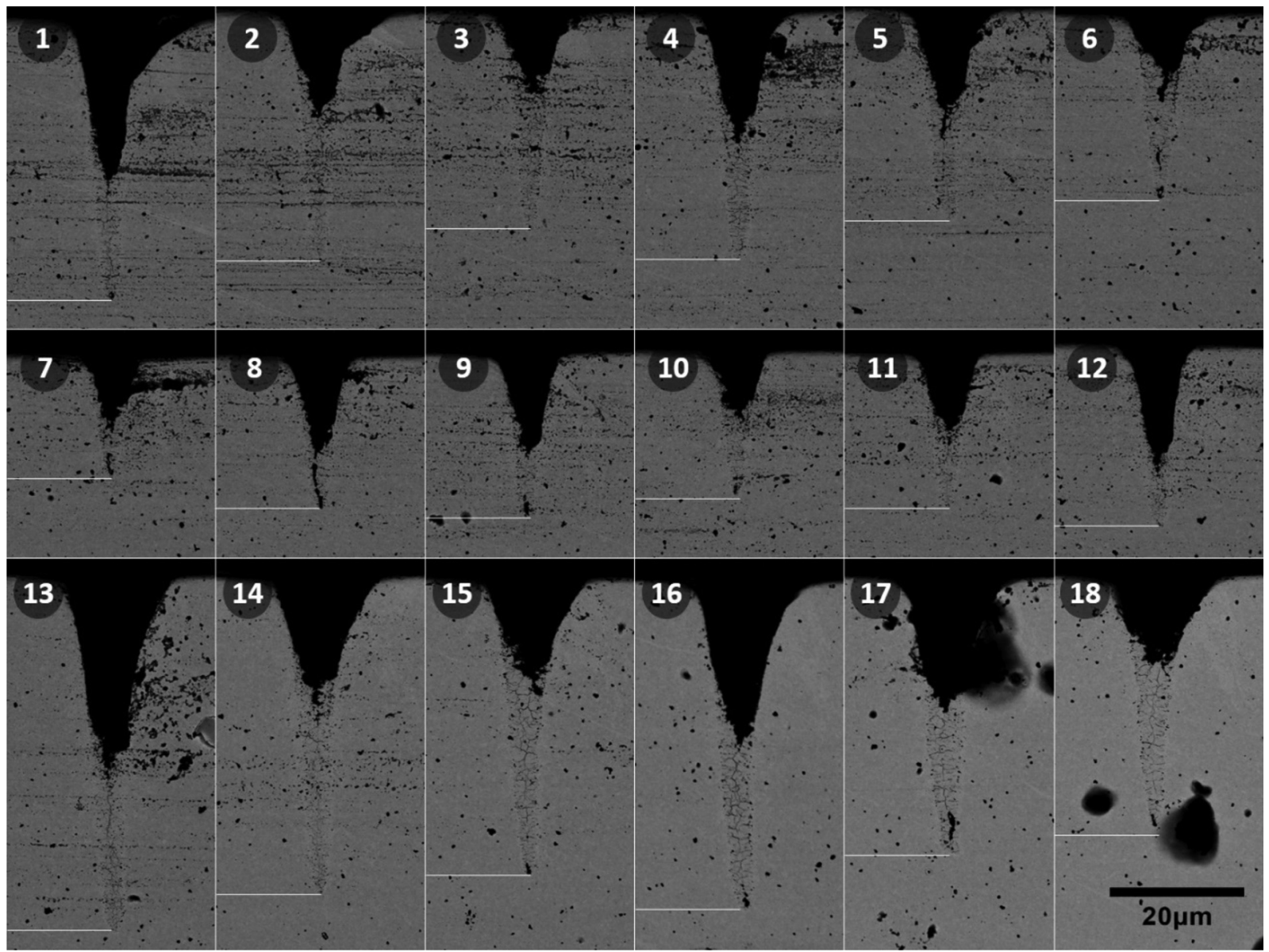

Fig. 2. YZ cross section of notches, with length of microcracked band marked with a white line. The laser ablation conditions for each notch are given in Table 1.

Table 2

Summary of notch and microcracked band lengths.

\begin{tabular}{|c|c|c|c|c|c|c|c|c|c|c|c|c|c|c|c|c|c|c|}
\hline Notch Number & 1 & 2 & 3 & 4 & 5 & 6 & 7 & 8 & 9 & 10 & 11 & 12 & 13 & 14 & 15 & 16 & 17 & 18 \\
\hline Notch length $(\mu \mathrm{m})$ & 24.1 & 15.5 & 12.1 & 19.4 & 15.3 & 9.0 & 10.8 & 14.3 & 15.0 & 10.4 & 11.6 & 17.9 & 28.7 & 19.2 & 15.5 & 24.4 & 20.2 & 13.2 \\
\hline Length of microcracked zone $(\mu \mathrm{m})$ & 17.6 & 21.2 & 20.0 & 17.2 & 15.8 & 18.6 & 7.3 & 8.4 & 9.3 & 11.2 & 11.4 & 9.1 & 24.0 & 27.9 & 28.4 & 24.1 & 20.7 & 24.0 \\
\hline Total length $(\mu \mathrm{m})$ & 41.7 & 36.7 & 32.1 & 36.6 & 31.1 & 27.6 & 18.1 & 22.7 & 24.3 & 21.6 & 23.0 & 27.0 & 52.7 & 47.1 & 43.9 & 48.5 & 40.9 & 37.2 \\
\hline
\end{tabular}

in this way is plotted in Fig. 4b, normalised by the area of the slice. At the beginning, during the first cuts, the slices contained the full notch width so that practically a $100 \%$ of cracked area was found along $\mathrm{Y}$ direction. This cracked area diminished along the $\mathrm{Z}$ direction very fast in the two specimens studied until the notch roots were reached at $\sim 5$ and $7 \mu \mathrm{m}$ from the starting slice for notches 7 and 13 , respectively. Below the notch root, the fraction of cracked area is very similar in both notches $(\sim 8 \%)$ and it decreases much more slowly in both specimens. The increase observed in specimen 7, marked with a circle in Fig. 4b, is related to the small hole present in front of the notch and shown in Fig. 4a. The cracked area dissapeared at a distance from the notch root of 10 and $24 \mu \mathrm{m}$, for specimen 7 and 13 , respectively.

The microcracking observed in front of the notch tip is not related to $\mathrm{t}-\mathrm{m}$ transformation since monoclinic phase was not detected in the microcracked band by confocal Raman spectroscopy, as shown in a previous work on 3Y-TZP [9]. It can be appreciated that the width of this microcracked band is very narrow ( $\sim 2 \mu \mathrm{m}$ for notch 7 and $\sim 4 \mu \mathrm{m}$ for notch 13 ), localised in the direction of the notch and with a high density of microcracks, most of them already interconnected (see supplementary material in the online version). The physical explanation cannot be related to photo-thermal effects and it seems likely related to thermomechanical waves induced by the laser ablation process since they are localised in the direction of the notch [16], [17] without producing any detectable $t-m$ transformation [9].

Regarding the conditions for fracture toughness determination from these notches, it can be seen that they are fullfilled since not only the tip radius of the notch is very sharp (of less than $1 \mu \mathrm{m}$ ) but also there is a non-transformed microcracked region in front of the notch so that, in principle, the total crack length can be taken as an unshielded edge straight crack with a length equal to that of the notch + microcracked band [5]. As the microcracked density is very high and almost all microcracks interconnected (see supplementary material), it is then expected that when the load is increased to fracture in a four point bending fracture test, the microcracked region will coalesce and form with the notch one sole crack that under higher loads will become unstable inducing failure [18]. Values obtained in previous studies by the authors in 3Y-TZP using the laser parameters of notch 1 (which is energetically closer to the examined notch 13; see Table 1) [9] and in $\mathrm{Si}_{3} \mathrm{~N}_{4}$ [10] are in agreement with results in literature in which fracture mechanics conditions for measuring fracture toughness were fullfilled. As all the parameters used here produce the same notch + microcracks 


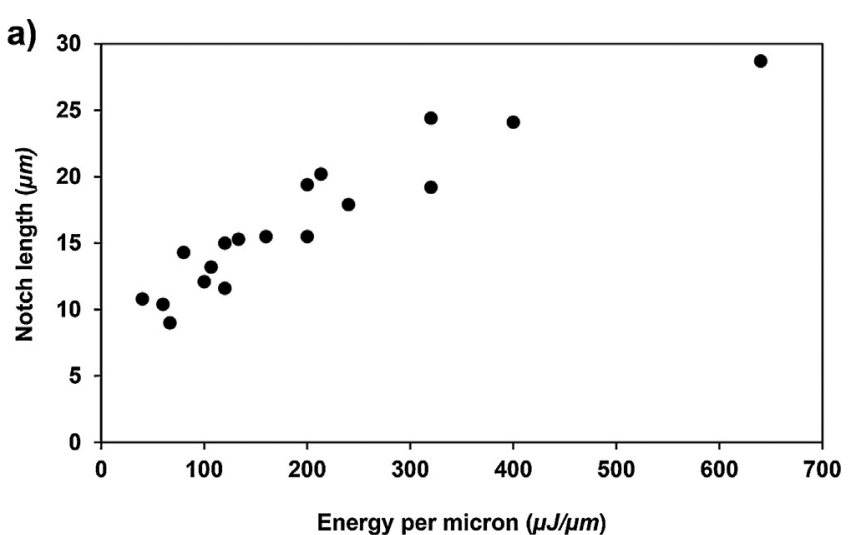

b)

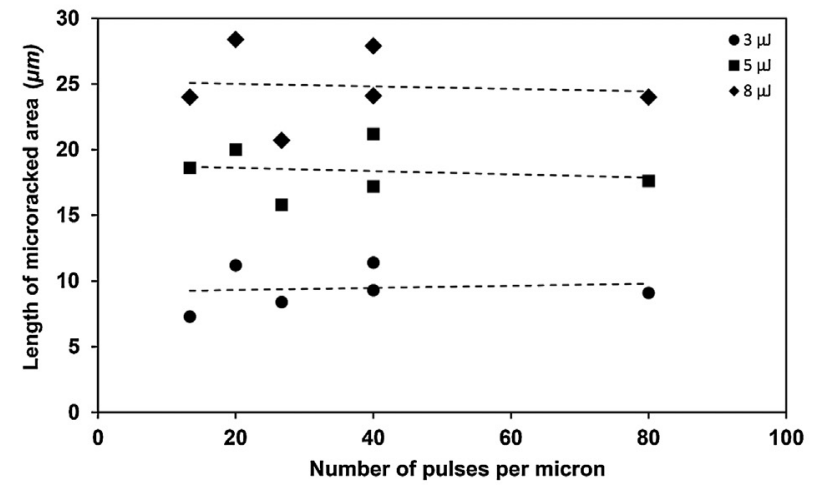

c)

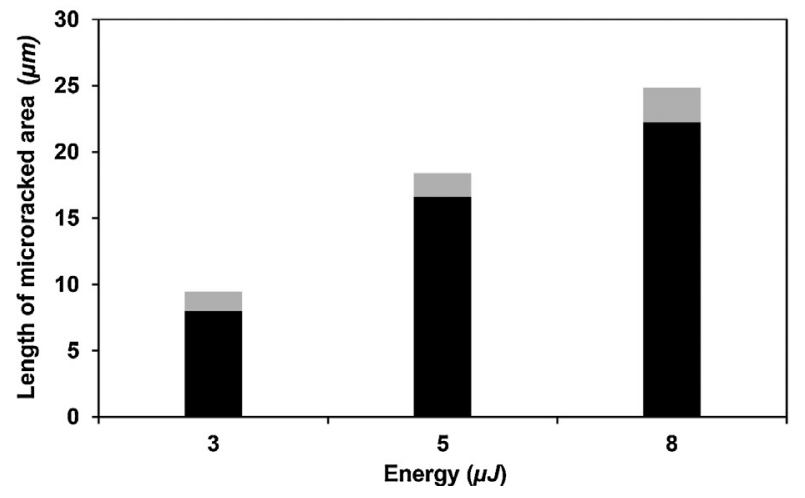

Fig. 3. a) The notch length in terms of energy per unit of length. b) The length of microcracked band in front of the notch versus the number of pulses per unit of length. c) Average of length of the length of the band versus pulse energy with standard deviation (in grey).

configuration and a small tip radius, we do not expect different values in the fracture toughness values obtained from these notches.

Here the notch has been machined on the surface of the specimen with the intention of producing very small cracks since fracture toughness of small cracks is the one that controls the strength of ceramics with natural cracks and R-curve behaviour. The UPLA technique can be also applied to a macroscospic starting blunt notch to make a very thin sharp notch at the root of the blunt notch [19]. Similarly a microcracked region would then be formed from which fracture toughness of long cracks could be determined. In this case the microcracked band in front of the ablation notch would be less than $1 \%$ of the macronotch + micronotch length so that it even may be a good first approximation not to take this microcracked band into consideration in the calculation of the fracture toughness. In any case, it is clearly revealed on the fracture surfaces after testing without the need to polish the

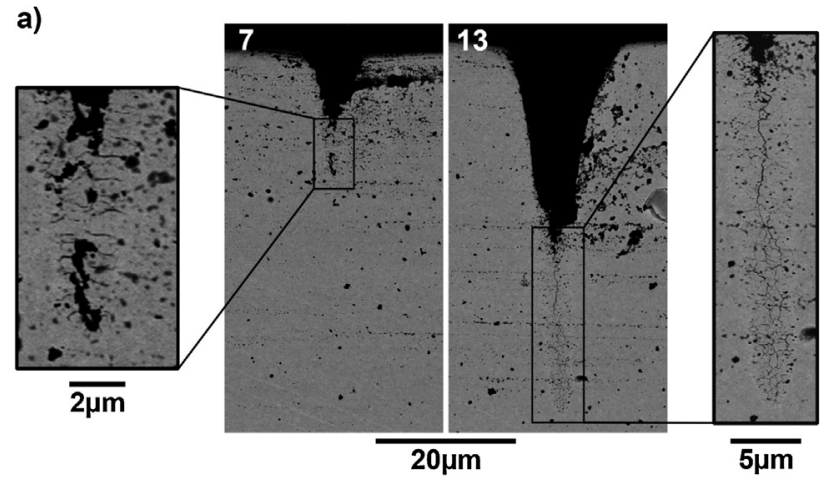

b)

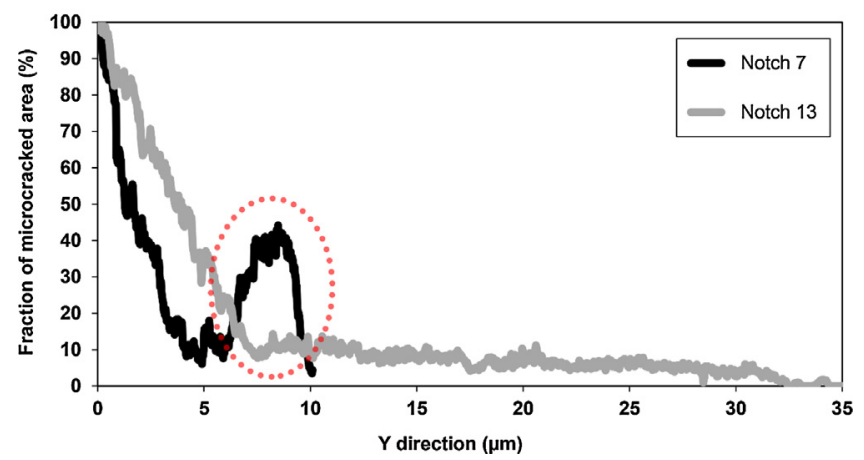

Fig. 4. a) Details of notch and microcracked band in specimens 7 and 13. b) Ratio of cracked area along the direction of the notch.

lateral surface for its detection [9], [10]. The relative small values obtained for fracture toughness of 3Y-TZP (around $4.1 \mathrm{MPa} \sqrt{ } \mathrm{m}$, see [9]), can be explained because the condition for unstable fracture for small unshielded cracks makes very unlikely the exploitation of the toughening from the modest and sharp R-curve present in 3YTZP with $330 \mathrm{~nm}$ grain size [20]. The condition of fracture in case of the presence of R-curve behaviour is reached before the crack can grow in an stable manner.

\section{Conclusions}

a) Ultra-short pulsed laser ablation can produce shallow surface notches on the surface of 3Y-TZP with a very directional narrow microcracked band in front of the notch tip and in the direction of the notch; b) the length of this band of microcracks depends on the laser pulse energy but not on the total energy absorbed during ablation of the notch; $c$ ) the set of parameters of ultrashort pulsed laser ablation which produces a sharper notch with a very well defined band of microcracks has been determined; d) the sharpness of the notch together with the length of microcracked fulfill the requirements of fracture mechanics for considering the crack length for fracture toughness determination as the notch length plus the length of the microcracked region.

\section{Acknowledgements}

Authors greatly acknowledge the financial support from "Ministerio de Economía, Industria y Competividad" of Spain (grant MAT2014-60720-R and the fellowship award received by MTV), the Secretaria d'Universitats i Recerca de la Generalitat de Catalunya (grant 2014-SGR-130), the European Commission (CREATe-Network, RISE Project $\mathrm{N}^{\circ}$ 644013) and to Dr. T. Trifonov for its assistance in the FIB/SEM equipment. PM also acknowledges support from Junta de Castilla y León (Project SA116U13, SA046U16) and MINECO (FIS2013-44174-P, FIS2015-71933-REDT). 
Appendix A. Supplementary data

Supplementary data associated with this article can be found, in the online version, at http://dx.doi.org/10.1016/j.jeurceramsoc. 2017.07.006.

\section{References}

[1] ASTM, 'C 1421-01b Standard Test Methods for Determination of Fracture Toughness of Advanced Ceramics at Ambient Temperature, 2002.

[2] T. Nishida, G. Pezzotti, T. Mangialardi, A.E. Paolini, Fracture mechanics evaluation of ceramics by stable crack propagation in bend bar specimens, Fract. Mech. Ceram. 11 (1996) 107-114.

[3] J. Kübler, Fracture Toughness of Ceramics Using the SEVNB Method; Round Robin. VAMAS Report No. 37, ESIS Document D2-99, EMPA, Dübendorf, 1999.

[4] R.J. Damani, R. Gstrein, R. Danzer, Critical notch-root radius effect in SENB-S fracture toughness testing, J. Eur. Ceram. Soc. 16 (1996) 695-702.

[5] T. Fett, Estimated stress intensity factors for semi-elliptical cracks in front of narrow circular notches, Eng. Fract. Mech. 64 (3) (1999) 357-362.

[6] I.V. Hertel, R. Stoian, D. Ashkenasi, A. Rosenfeld, E.E.B. Campbell, On the physics of material processing with femtosecond lasers, RIKEN Rev. 32 (32) (2001) 23-30.

[7] A.N. Samant, N.B. Dahotre, Laser machining of structural ceramics-A review, J. Eur. Ceram. Soc. 29 (6) (2009) 969-993.

[8] L. Lucas, J. Zhang, Femtosecond laser micromachining: a back-to-basics primer, Ind. Laser Solut. (4) (2012) 1-22.

[9] M. Turon-Vinas, M.J. Anglada, Fracture toughness of zirconia from a shallow notch produced by ultra-short pulsed laser ablation, J. Eur. Ceram. Soc. 34 (15) (2014) 3865-3870.
[10] M. Turon-Vinas, M. Anglada, Assessment in Si3N4 of a new method for determining the fracture toughness from a surface notch micro-machined by ultra-short pulsed laser ablation, J. Eur. Ceram. Soc. 35 (6) (2015) 1737-1741.

[11] X. Wang, A. Atkinson, On the measurement of ceramic fracture toughness using single edge notched beams, J. Eur. Ceram. Soc. 35 (13) (2015) 3713-3720.

[12] H.D. Carlton, J.W. Elmer, D.C. Freeman, R.D. Schaeffer, O. Derkach, G.F. Gallegos, Laser notching ceramics for reliable fracture toughness testing, J. Eur. Ceram. Soc. 36 (1) (2016) 227-234.

[13] L.V. Zhigilei, P.B.S. Kodali, B.J. Garrison, On the threshold behavior in laser ablation of organic solids, Chem. Phys. Lett. 276 (3-4) (1997) 269-273.

[14] R. Stoian, D. Ashkenasi, A. Rosenfeld, E.E.B. Campbell, Coulomb explosion in ultrashort pulsed laser ablation of Al2O3, Phys. Rev. B 62 (19) (2000) 167-173.

[15] R.A. Delgado-Ruíz, J.L. Calvo-Guirado, P. Moreno, J. Guardia, G. Gomez-Moreno, J.E. Mate-Sánchez, P. Ramirez-Fernández, F. Chiva, Femtosecond laser microstructuring of zirconia dental implants, J. Biomed. Mater. Res. Part B 96 (1) (2011) 91-100.

[16] S. Heiroth, J. Koch, T. Lippert, A. Wokaun, D. Günther, F. Garrelie, M. Guillermin, Laser ablation characteristics of yttria-doped zirconia in the nanosecond and femtosecond regimes, J. Appl. Phys. 107 (1) (2010) 014908.

[17] H. Hu, X. Wang, H. Zhai, N. Zhang, P. Wang, Generation of multiple stress waves in silica glass in high fluence femtosecond laser ablation, Appl. Phys. Lett. 97 (6) (2010) 061117.

[18] M. Ortiz, Microcrack coalescence and macroscopic crack growth initiation in brittle solids, Int. J. Solids Struct. 24 (3) (1988) 231-250.

[19] W. Zhao, P. Rao, Z. Ling, A new method for the preparation of ultra-sharp $\mathrm{V}$-notches to measure fracture toughness in ceramics, J. Eur. Ceram. Soc. 34 (15) (2014) 4059-4062.

[20] D. Casellas, A. Feder, L. Llanes, M. Anglada, Fracture toughness and mechanical strength of Y-TZP/PSZ, Scr. Mater. 45 (2) (2001) 213-220. 